\title{
Editorial
}

\section{Deep Rock Behaviour in Engineering Environments}

\author{
Fengqiang Gong $\mathbb{D},{ }^{1}$ Jianping Zuo $\mathbb{D},{ }^{2}$ Xihong Zhang $\mathbb{D},{ }^{3}$ and Richeng Liu $\mathbb{D}^{4}$ \\ ${ }^{1}$ Southeast University, Nanjing, China \\ ${ }^{2}$ University of Mining and Technology (Beijing), Beijing, China \\ ${ }^{3}$ Curtin University, Perth, Australia \\ ${ }^{4}$ Nagasaki University, Nagasaki, Japan \\ Correspondence should be addressed to Fengqiang Gong; fengqiangg@126.com
}

Received 30 November 2021; Accepted 30 November 2021; Published 16 December 2021

Copyright (c) 2021 Fengqiang Gong et al. This is an open access article distributed under the Creative Commons Attribution License, which permits unrestricted use, distribution, and reproduction in any medium, provided the original work is properly cited.

This special issue compiles seventy-six original papers covering the following topics: mechanical properties and fracture behavior of deep rock, rock failure behavior under multifield coupling and multiscale systems, dynamic failure characteristics and constitutive properties of deep rock, mechanical behaviours of rock fractures during shearing, energy evolution characteristics during rock fracturing, experimental or numerical simulation of rockbursts, failure mechanism of spalling in deep tunnels, rock and structure response under blast and impulsive loading, and prevention and control of disasters in deep rock engineering.

Nineteen articles in this special issue are related to mechanical properties and fracture behavior of deep rock. $\mathrm{J}$. Li et al. explore the deep rock mechanics through mechanical analysis of hard rock in situ coring system. J. Li et al. experimentally study the adsorption pore structure and gas migration of coal reservoir using low-field nuclear magnetic resonance. $\mathrm{X}$. Xi et al. model the crack initiation and propagation of notched rock beam under the three-point bending load. Based on acoustic emission, Q. Hao et al. investigate the stress threshold of deep buried coal rock under quasistatic strain rate; $C$. Wang et al. experimentally study the fracture patterns and crack propagation of sandstone. L. Dong et al. also experimentally determine the Poisson's ratio for intact rocks and its variation as deformation develops. Based on digital images, $\mathrm{H}$. Cui et al. conduct numerical test study on the microscale failure modes and fractal analysis of lower Cambrian shale. Considering the bedding directivity, $\mathrm{X}$. Ou et al. perform static and dynamic Brazilian tests on layered slate. Y. Yuan et al. experimentally investigate the mechanical properties of prefabricated single-cracked red sandstone under uniaxial compression. J. Liu et al. study the fracture evolution process of rock-like specimens containing a closed rough joint based on $3 \mathrm{D}$ printing technology. S. Huang et al. investigate the creep mechanics of high stress soft rock under grade unloading. Z. Zhao et al. investigate the in situ curing of a polymer film for light-proof coring of deep rocks with preservation of rock quality and moisture. $\mathrm{D}$. Li et al. conduct numerical test research on the loading rate effect of rock mass with transfixion sawtooth structural plane. Y. Zhao et al. numerically analyze the mechanical behavior and failure mode of jointed rock under uniaxial tensile loading. X. Zhu et al. present a complex network model for analysis of fractured rock permeability. Based on Griffith's strength theory, S. Wang et al. also give a discrete element modeling of crack initiation stress of marble. A paper by C. Chen et al. experimentally investigates the deformation and strength behavior of marble with complex loadingunloading stress path. K. Yang et al. also experimentally investigate the mechanical characteristics and the failure mechanism of coal-rock composite under uniaxial load. $\mathrm{R}$. $\mathrm{Wu}$ et al. describe the effect of material properties and strain rate on fragmentation of anisotropic rock.

Five papers involve the rock failure behavior under multifield coupling and multiscale systems. Z. Zhang et al. numerically simulate the rock failure process with a $3 \mathrm{D}$ grain-based rock model. P. Li et al. numerically model the interaction between hydraulic fractures and natural fractures by using the extended finite element method. Based on dry- 
coupled ultrasonic monitoring technology, Y. Liu et al. analyze the ultrasonic spectrum of granite damage evolution. B. Zhu et al. identify the coupling effect of creep deformation and prestress loss of anchored jointed rock. N. Shen et al. present the effects of water and $\mathrm{scCO}_{2}$ injection on the mechanical properties of granite at high temperatures.

Five articles are associated with the dynamic failure characteristics and constitutive properties of deep rock. Y. Zhu et al. illustrate a novel fatigue damage model of rock considering temperature effects. R. Xu et al. experimentally investigate the brittleness and rockburst proneness of three kinds of hard rocks under uniaxial compression. K. Man et al. conduct dynamic tensile test of granite and analyze its tensile sensitivity. F. Li et al. study the damage constitutive model of brittle rocks considering stress dropping characteristics. B. Guo et al. investigate the triaxial strength criteria in Mohr stress space for intact rocks.

Four articles reveal the energy evolution characteristics during rock fracturing. Q. Ma et al. give the dynamic behavior and energy evolution characteristic of deep roadway sandstone containing weakly filled joint at various angles. Using AE and DIC methods, a paper by J. Pan et al. studies the deformation behavior and energy evolution of conjugate jointed rock. X. Cheng et al. study the mechanical properties and energy dissipation of gas coal under dynamic and static loads. X. Hao et al. also show the failure behavior and energy storage and release of hard coal under different static and dynamic loading states.

Five articles in this special issue investigate the rock and structure responses under blast and impulsive loading. Y. Liu et al. study the static and dynamic fracturing properties of marble after being damaged dynamically. J. Wu et al. experimentally investigate the dynamic compression mechanical properties of frozen fine sandstone. B. Cheng et al. present a study on cut blasting with large diameter charges in hard rock roadways. B. Xie et al. numerically simulate the split Hopkinson pressure bar tests for the combined coal rock by using the Holmquist-Johnson-Cook model and case analysis of outburst. K. Man et al. analyze the frequency spectrum and wavelet packet of blasting vibration signals for different charge structures in blasting peripheral holes.

Thirty-four papers involve the prevention and control of disasters in deep rock engineering. J. Hao et al. present the karst water pressure's varying rule and its response to overlying strata movement in coal mine. Based on magnetic field trigger controller, G. Liu et al. give the innovative design of deep in situ pressure retained coring. C. Xie et al. study the instability mechanism and grouting reinforcement repair of large-scale underground stopes. C. Peng et al. investigate the failure mechanism of jointed rock slopes based on discrete element method. J. Wei et al. numerically study the damage to rock surrounding an underground coal roadway excavation. Combined with the surrounding rock stability index, J. Chang et al. study the instability characteristics and bolt support in deep mining roadways taking Pansan Coal Mine as an example. G. Hou et al. experimentally analyze the deformation and acoustic emission characteristics of arch roadway under different unloading rates. $Z$. He et al. design and verify a deep rock corer with retaining the in situ temperature. X. Zhao et al. analyze the support design in weak rock drift using a systematic approach. T. Wang et al. show a flowchart of DEM modeling stability analysis of large underground powerhouse caverns. C. Wang et al. reveal the stability mechanism and repair method of U-shaped steel reverse arch support in soft floor roadway. With a case study of Yima mining area, Y. Li discuss the mechanism of coal bump among mine groups under the control of large geological body. G. Guo et al. study the key stratum location and characteristics on the mining of extremely thick coal seam under goaf. Based on distributed optical fibre sensing technology, Y. Li et al. investigate the pressure relief borehole effects in situ testing. B. Li et al. present the short-term gradation loading creep properties and failure characteristics of high-strength fly ash concrete for underground engineering. L. Peng et al. research the fault activation law in deep mining face and mechanism of rockburst induced by fault activation. $\mathrm{H}$. Wu et al. analyze the influence law of burial depth on surrounding rock deformation of roadway. C. Ma et al. demonstrate the application of geological core ground reorientation technology on in situ stress measurement of an over kilometer deep shaft. H. Ma et al. experimentally study the desorption characteristics of coalbed methane under variable loading and temperature in deep and high geothermal mine. W. Wang et al. study the deformation mechanism and supporting countermeasures of compound roofs in loose and weak coal roadways. Z. He et al. assess the hazardous rock block stability based on vibration feature parameters. H. Ren et al. describe the classification and application of roof stability of bolt supporting coal roadway based on BP neural network. S. Zhao et al. investigate the liquefaction properties and postliquefaction volumetric strain of calcareous sand in dredger fill site. C. Zhao et al. study the stress distribution law of fully anchored bolt and analyze the influencing factors under the condition of surrounding rock deformation. F. Du et al. reveal the evolution law of fracture field in full-mechanized caving mining of double system and extra-thick coal seam. M. Wang et al. propose key factors affecting the deformation and failure of surrounding rock masses in large-scale underground powerhouses. Y. Wu et al. present a mechanical model of underground shaft coal pocket and deformation of silo wall in coal mines. W. Ping et al. conduct a case study on gob-side entry retaining technology in deep coal mine of Xin Julong, China. Z. Liao et al. perform experimental and theoretical investigation of overburden failure law of fully mechanized work face in steep coal seam. X. Wu et al. study the stage failure mechanism and stability control of surrounding rock of repeated mining roadway. G. Deng et al. numerically simulate the evolution of mining-induced fracture network in a coal seam and its overburden under the top coal caving method. K. Ma et al. study the mechanism of influence of mining speed on roof movement based on microseismic monitoring. Based on discrete element method, C. Peng et al. investigate the failure mechanism of jointed rock slopes. L. Li et al. analyze the influencing factors on anomalously low friction effect in block rock mass. 
Additional papers conduct experimental or numerical investigations of rockburst. J. Yang et al. comparatively study the excavation damage and rockburst of the deeply buried Jinping II diversion tunnels using a TBM and the drilling-blasting method. C. Zhang et al. study the impact tendency of coal and rock mass based on different stress paths. Lu et al. propose an extension failure criterion for brittle rock. Based on CT scanning, P. Liang et al. experimentally investigate the formation of rockburst pits in circular tunnel.

\title{
Conflicts of Interest
}

The guest editors declare that no conflicts of interest are involved in the publication of this special issue.

\section{Acknowledgments}

The editor team would like to show great gratitude to the authors and reviewers for their time and efforts spent on this special issue. In addition, they sincerely hope that this issue will contribute to the application improvement of deep rock engineering.

\author{
Fengqiang Gong \\ Jianping Zuo \\ Xihong Zhang \\ Richeng Liu
}

